\title{
EVALUATION OF INCIDENTAL LUMBAR SPONDYLOLYSIS BY COMPUTED TOMOGRAPHY
}

\author{
Amarnath Chellathurai ${ }^{1}$, Sivakumar Kannappan², Felcy Melba³, Sathyan Gnanasigamani4, Suhasini Balasubramaniam ${ }^{5}$
}

1 Professor, Department of Radiodiagnosis, Stanley Medical College, Chennai, Tamilnadu.

${ }^{2}$ Senior Resident, Department of Radiodiagnosis, Stanley Medical College, Chennai, Tamilnadu.

3Junior Resident, Department of Radiodiagnosis, Stanley Medical College, Chennai, Tamilnadu.

4 Professor, Department of Radiodiagnosis, Stanley Medical College, Chennai, Tamilnadu.

${ }^{5}$ Associate Professor, Department of Radiodiagnosis, Stanley Medical College, Chennai, Tamilnadu.

\section{BACKGROUND}

\section{ABSTRACT}

Spondylolysis is defined as a defect in the pars interarticularis of the vertebral arch, which is a bony bridge connecting the superior and the inferior articular facet joints.

Aims and Objectives: To determine the incidental occurrence of lumbar spondylolysis, the common site and type of involvement and the associated degenerative disorders in the patients in an unselected population.

\section{MATERIALS AND METHODS}

This is a cross-sectional study in which incidental spondylolysis was evaluated for 852 patients (462 females and 380 males) who underwent multidetector (16 slice) CT abdomen/ (Kidney Ureter Bladder) using bone and soft tissue algorithm.

Overview of Literature- There are very less number of studies regarding the prevalence of incidental spondylolysis, the common site and the type of involvement in a developing country.

\section{RESULTS}

CT Abdomen/ KUB imaging showed higher prevalence of incidental lumbar spondylolysis. Most common level involved was L5 vertebra, the common type was isthmic. Age wise distribution of type of spondylolysis and grading of listhesis was significant.

\section{CONCLUSION}

CT Abdomen/ KUB imaging of an unselected Indian population showed higher prevalence of incidental lumbar spondylolysis. The prevalence of isthmic type is higher and its progression to spondylolisthesis increases with advancing age.

\section{KEY WORDS}

Lumbar, Spondylolysis, Spondylolisthesis, Facet Hypertrophy.

HOW TO CITE THIS ARTICLE: Chellathurai A, Kannappan S, Melba F. Evaluation of incidental lumbar spondylolysis by computed tomography. J. Evolution Med. Dent. Sci. 2018;7(21):2543-2545, DOI: 10.14260/jemds/2018/572

\section{BACKGROUND}

Spondylolysis is defined as a defect in the pars interarticularis of the vertebral arch, which is a bony bridge connecting the superior and the inferior articular facet joints. Spondylolysis can either be asymptomatic or can cause significant low back pain.[1]

There are five categories of spondylolysis, ${ }^{[1,2]}$ as modified by Wiltse-

Type I- Congenital abnormalities due to attenuated pars.

Type II- Stress fracture or acute fracture in the pars interarticularis.

Type III- Degenerative type.

Type IV- Traumatic type.

Type V- Pathological- tumours and infections.

Spondylolisthesis is defined as the forward displacement of the superior vertebra on its adjacent caudal vertebra.[1,3]

'Financial or Other Competing Interest': None.

Submission 26-04-2018, Peer Review 10-05-2018,

Acceptance 12-05-2018, Published 21-05-2018.

Corresponding Author:

Sivakumar Kannappan

Senior Resident of Radiology,

Department of Radiodiagnosis,

Stanley Medical College, Chennai,

Tamilnadu.

E-mail:drksiva82@gmail.com.

DOI: $10.14260 /$ jemds $/ 2018 / 572$
Grading of spondylolisthesis was estimated using the Meyerding classification: Grade 0, No slip; Grade I, $\geq 5 \%$ and $<25 \%$; Grade II, 26-50\%; Grade III, 51-75\%; Grade IV, 76$100 \%$; and Grade V, complete slippage.[4]

As the present study was conducted in an unselected population in India for the first time, our study represent a valuable addition to the existing literature. Here in this study, the incidental occurrence of lumbar spondylolysis, the common site of involvement and the associated degenerative disorders were evaluated in patients who underwent CT abdomen for abdominal, pelvic, general illness and other urological conditions unrelated to low backache.

\section{MATERIALS AND METHODS}

This is a cross-sectional study done in a sample size of 852 patients who underwent CT abdomen/ kidney ureter and bladder for causes unrelated to lower back pain from June 2017 to December 2017.

\section{Inclusion Criteria}

Patients of all ages who underwent Computed Tomography abdomen and pelvis/ KUB. Exclusion criteria: Patients with recent history of trauma, known case of orthopaedic, neurological and degenerative spine diseases.

\section{CT Protocol}

Multidetector CT (Toshiba Alexion 16 slice) using a sequential scan protocol with a slice thickness of $0.8 \mathrm{~mm}$ and 
interval thickness of $5 \mathrm{~mm}(120 \mathrm{KVp}, 400 \mathrm{~mA})$ during a normal breath hold with exposure time of $5.7 \mathrm{sec}$. The CT scans were evaluated by two experienced radiologists with ten years of experience in musculoskeletal radiology.

Spondylolysis is seen as a defect extending through the pars interarticularis. This was demonstrated well on sagittal 2D reconstructions. The entire lumbar spine and the posterior elements of lumbar vertebra was reviewed using bone windows. The level of spondylolysis, unilateral or bilateral, type of spondylolysis were evaluated and analysed. The grading of spondylolisthesis was done for those patients with bilateral spondylolysis excluding those with unilateral spondylolysis.

The data were analysed with IBM SPSS software version 23. To find the significance in categorical data, Chi-square test was used.

\section{RESULTS}

Out of 852 patients, spondylolysis was found in 107 patients with a prevalence of $12.5 \%$. Spondylolysis involving L5 vertebra was found in 100 patients (Fig. 3, 4) and L4 level in 5 patients.

Multilevel spondylolysis was found in two patients. One patient had combined L4 and L5 spondylolysis with degenerative changes. Another patient had L3, L4 and L5 levels spondylolysis with extensive degenerative changes.

Among them 80 (74.8\%) patients presented with bilateral spondylolysis and $27(25.2 \%)$ patients with unilateral spondylolysis (Table 1).

Out of 80 patients with bilateral spondylolysis, 54 patients demonstrated spondylolisthesis, of which 40 were grade I and 14 were grade II. Those patients with bilateral spondylolysis and with anterolisthesis showed associated degenerative changes including end plate sclerosis, vacuum discs and facet hypertrophy (Fig. 1, 2). Grade III, IV spondylolisthesis was not seen in any of the patients.

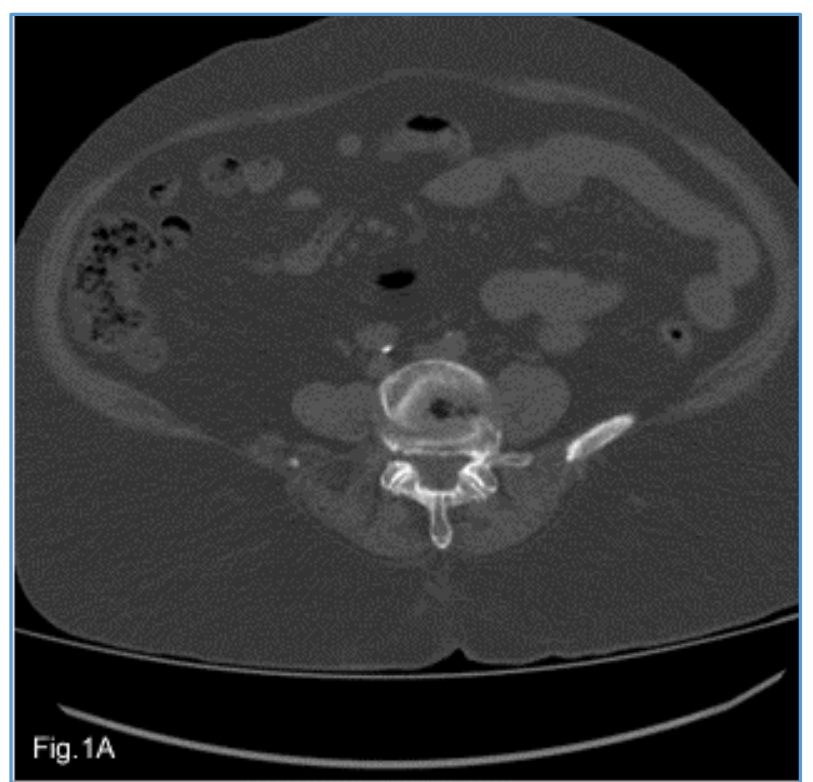

Figure 1A. Shows Axial Section of Lumbar Spondylolysis at L4 Level with Type 1 Spondylolisthesis of L4 over L5 Vertebra with Degenerative Changes

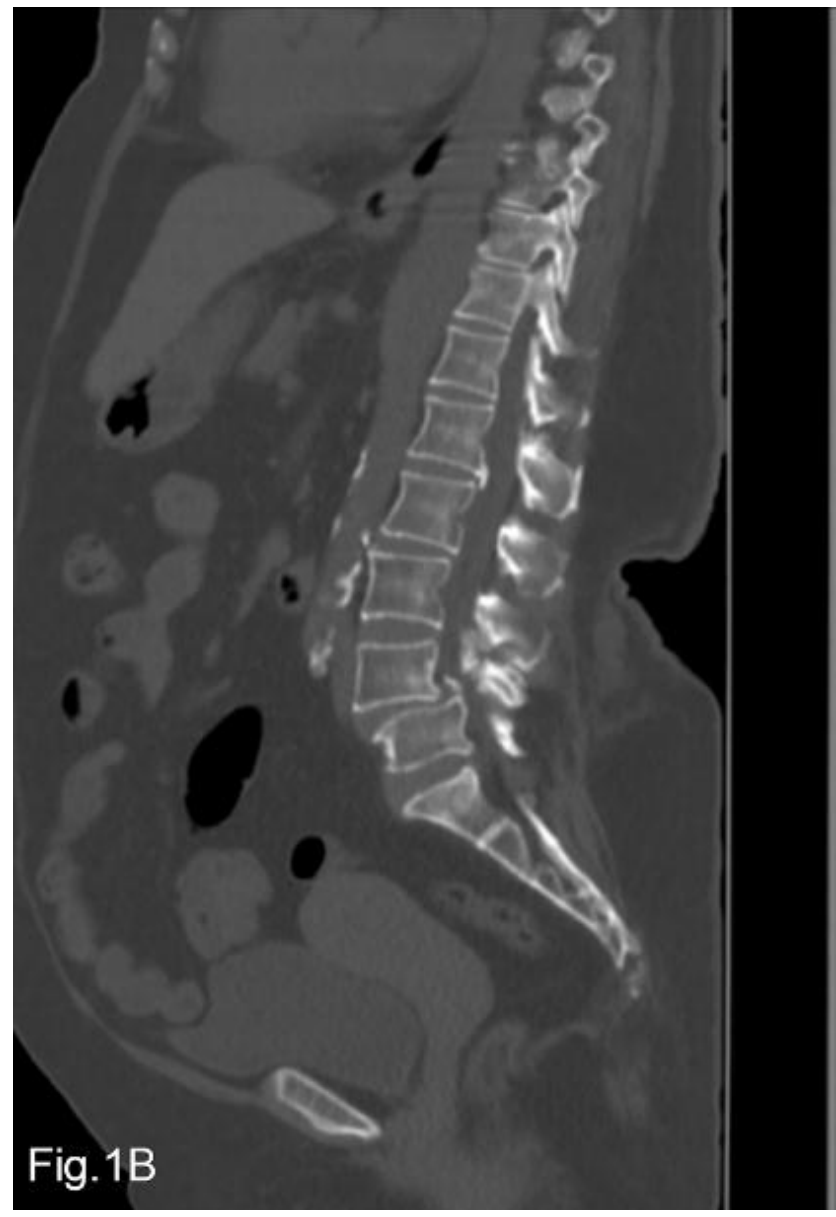

Figure 1B. Shows Sagittal Section of Lumbar Spondylolysis at L4 Level with Type 1 Spondylolisthesis of L4 over L5 Vertebra

\begin{tabular}{|c|c|c|}
\hline Age Group & $\begin{array}{c}\text { Unilateral } \\
\text { Spondylolysis }\end{array}$ & $\begin{array}{c}\text { Bilateral } \\
\text { Spondylolysis }\end{array}$ \\
\hline Less than 20 yrs. & $342.9 \%$ & $457.1 \%$ \\
\hline $20-40$ & $1233.3 \%$ & $2466.7 \%$ \\
\hline $40-60$ & $718.2 \%$ & $3681.8 \%$ \\
\hline More than 60 yrs. & $520 \%$ & $1680 \%$ \\
\hline Total & $25.2 \%$ & $74.8 \%$ \\
\hline
\end{tabular}

P value- 0.278 , not significant.

\begin{tabular}{|c|c|c|c|c|c|c|}
\hline$\underset{0}{\mathscr{\varpi}}$ & 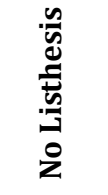 & 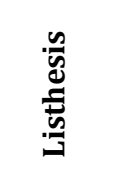 & 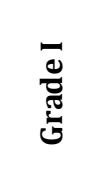 & $\begin{array}{l}= \\
\frac{0}{\pi} \\
\frac{\pi}{5}\end{array}$ & 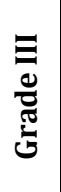 & $\begin{array}{l}\underset{0}{0} \\
\frac{0}{0} \\
\frac{\pi}{v}\end{array}$ \\
\hline $\begin{array}{c}\text { Less than } 20 \\
\text { yrs. }\end{array}$ & $\begin{array}{c}4 \\
100 \%\end{array}$ & 0 & 0 & 0 & 0 & 0 \\
\hline $20-40$ yrs. & $\begin{array}{c}8 \\
33.3 \% \\
\end{array}$ & $\begin{array}{c}16 \\
67.7 \% \\
\end{array}$ & $\begin{array}{c}14 \\
58.3 \% \\
\end{array}$ & $\begin{array}{c}2 \\
8.3 \% \\
\end{array}$ & 0 & 0 \\
\hline $40-60$ yrs. & $\begin{array}{c}13 \\
36.1 \% \\
\end{array}$ & $\begin{array}{c}23 \\
63.9 \% \\
\end{array}$ & $\begin{array}{c}17 \\
47.2 \% \\
\end{array}$ & $\begin{array}{c}6 \\
16.7 \% \\
\end{array}$ & 0 & 0 \\
\hline $\begin{array}{l}\text { More than } \\
60 \text { yrs. }\end{array}$ & $\begin{array}{c}1 \\
6.3 \%\end{array}$ & $\begin{array}{c}15 \\
93.7 \%\end{array}$ & $\begin{array}{c}9 \\
56.3 \%\end{array}$ & $\begin{array}{c}6 \\
37.5 \%\end{array}$ & 0 & 0 \\
\hline Total & $\begin{array}{c}26 \\
32.5 \% \\
\end{array}$ & $\begin{array}{c}54 \\
67.5 \% \\
\end{array}$ & $\begin{array}{c}40 \\
50 \% \\
\end{array}$ & \begin{tabular}{|c|}
14 \\
$17.5 \%$ \\
\end{tabular} & 0 & $\mathbf{0}$ \\
\hline \multicolumn{7}{|c|}{ Table 2. Analysis of Grading of Spondylolisthesis } \\
\hline
\end{tabular}


*Unilateral spondylolysis patients were not included for the analysis of listhesis

Chi-square test: p-value was found to be 0.009 , significant.

\begin{tabular}{|c|c|c|c|}
\hline Age Group & $\begin{array}{l}\text { Degenerative } \\
\text { Spondylolysis }\end{array}$ & $\begin{array}{c}\text { Dysplastic } \\
\text { Spondylolysis }\end{array}$ & $\begin{array}{c}\text { Isthmic } \\
\text { Spondylolysis }\end{array}$ \\
\hline $\begin{array}{c}\text { Less than } 20 \\
\text { yrs. }\end{array}$ & 0 & $1(14.3 \%)$ & $6(85.7 \%)$ \\
\hline $20-40$ & $6(16.7 \%)$ & 0 & $30(83.30 \%)$ \\
\hline $40-60$ & $16(36.4 \%)$ & 0 & $28(63.6 \%)$ \\
\hline $\begin{array}{c}\text { More than } 60 \\
\text { yrs. }\end{array}$ & $8(40 \%)$ & 0 & $12(60 \%)$ \\
\hline Total & $30(28 \%)$ & $1(1 \%)$ & $76(71 \%)$ \\
\hline \multicolumn{4}{|c|}{ Table 3. Analysis of Types of Spondylolysis } \\
\hline
\end{tabular}

$P$ value- 0.001 , found to be significant.

*Type IV (traumatic) and V (pathological) were excluded from the study and hence not included in the analysis.

\section{DISCUSSION}

Out of the 852 patients, spondylolysis was detected in 107 patients as an incidental finding. Our study reported higher prevalence rate of lumbar spondylolysis in the general population than previously reported. The $12.5 \%$ rate identified in our study is nearly double the prevalence rate detected in previous studies,5,6 which used conventional radiography for investigation.

According to Sohail et al the prevalence of incidental spondylolysis was $6,1 \%$ in large community based population in Pakistan, a developing Asian country.[7] Similarly study by Belfi et al showed a prevalence of $5.7 \%$ spondylolysis on examining 510 consecutive patients with abdomen CT.

Clinical studies have suggested that the prevalence of spondylolysis in the Native American and Eskimo populations is quite high and ranges from 17 to $53 \%,[8,9]$

According to Kalichman et al, the prevalence of incidental spondylolysis in the American population aged 40 - 80 who were selected for Framingham Heart study. The prevalence rate $(11.3 \%)$ was higher than previous studies, because it was conducted in a predominantly older population with low backache.

The higher rate of spondylolysis identified in this study can be attributed to the higher physical activity involving frequent stress to the lumbar spine and also to genetic predisposition.

According to Syrmou et al, the incidence of spondylolysis at $\mathrm{L} 5$ vertebral level is (85-95\%) and L4 level is (5 - 15\%). Similarly, in our study, higher incidence was found at L5 level. According to Kwang-Hwan Park et al, the incidence of multiple lumbar spondylolysis appears to vary between $1.2 \%$ to $5.6 \% .{ }^{[10,11]}$ In our study, multilevel spondylolysis was seen in $1.8 \%$.

In addition, the types of spondylolysis was analysed. The most common type was isthmic. The isthmic type of spondylolysis was noted in 76 (71\%) patients and degenerative spondylolysis was noted in 30 (28\%). Only one patient had dysplastic spondylolysis (Table 2). Of the 80 patients with bilateral spondylolysis spondylolisthesis was found in 54 patients (67.5\%).

The incidence of degenerative spondylolysis was more common in the older age group of more than 60 years' age group (40\%). Analysis of age distribution of type of spondylolysis was significant (Table 3 ).

In our study, the prevalence of spondylolisthesis is $6.3 \%$ compared to $3.1 \%$ prevalence of spondylolisthesis found by Belfi et al.

Spondylolisthesis was found significantly more common in older population.

Sample size of our study was limited. All types of spondylolysis could not be studied in detail.

\section{CONCLUSION}

CT Abdomen/ KUB imaging of an unselected Indian population showed higher prevalence of incidental lumbar spondylolysis. The prevalence of isthmic type is higher. The progression of spondylolysis to spondylolisthesis increases with advancing age.

\section{REFERENCES}

[1] Syrmou E, Tsitsopoulos PP, Marinopoulos D, et al. Spondylolysis: a review and reappraisal. Hippokratia 2010;14(1):17-21.

[2] Wiltse LL, Newman PH, Macnab I. Classification of Spondylolisis and spondylolisthesis. Clin Orthop Relat Res 1976;117:23-9.

[3] Kalichman L, Kim DH, Li L, et al. Spondylolysis and spondylolisthesis: prevalence and association with low back pain in the adult community-based population. Spine (Phila Pa 1976) 2009;34(2):199205.

[4] Meyerding HW. Spondylolisthesis. Surg Gynaecol Obstet 1932;54:371-7.

[5] Fredrickson BE, Baker D, McHolick WJ, et al. The natural history of spondylolysis and spondylolisthesis. J Bone Joint Surg Am 1984;66(5):699-707.

[6] Virta L, Ronnemaa T, Osterman K, et al. Prevalence of isthmic lumbar spondylolisthesis in middle-aged subjects from eastern and western Finland. J Clin Epidemiol 1992;45(8):917-22.

[7] Khan SA, Sattar A, Khanzada U. et al. Facture of the pars interarticularis with or without spondylolisthesis in an adult population in a developing country: evaluation by multidetector computed tomography. Asian Spine J 2017;11(3):437-43.

[8] Baker DR, McHolick W. Spondylolischisis and spondylolisthesis in children. J Bone Joint Surg Am 1956;38:933-4.

[9] Simper LB. Spondylolysis in Eskimo skeletons. Acta Orthop Scand 1986;57(1):78-80.

[10] Stewart TD. The age incidence of neural-arch defects in Alaskan natives, considered from the standpoint of etiology. J Bone Joint Surg Am 1953;35-A(4):937-50.

[11] Park KH, Ha JW, Kim HS, et al. Multiple levels of lumbar spondylolysis - a case report. Asian Spine J 2009;3(1):35-8. 